\title{
Contributions of individual variation in temperature, solar radiation and precipitation to crop yield in the North China Plain, 1961-2003
}

\author{
Chao Chen • Walter E. Baethgen • Andrew Robertson
}

Received: 30 July 2011 / Accepted: 22 May 2012

(C) Springer Science+Business Media B.V. 2012

\begin{abstract}
An understanding of the relative impacts of the changes in climate variables on crop yield can help develop effective adaptation strategies to cope with climate change. This study was conducted to investigate the effects of the interannual variability and trends in temperature, solar radiation and precipitation during 1961-2003 on wheat and maize yields in a double cropping system at Beijing and Zhengzhou in the North China Plain (NCP), and to examine the relative contributions of each climate variable in isolation. 129 climate scenarios consisting of all the combinations of these climate variables were constructed. Each scenario contained 43 years of observed values of one variable, combined with values of the other two variables from each individual year repeated 43 times. The Agricultural Production Systems Simulator (APSIM) was used to simulate crop yields using the ensemble of generated climate scenarios. The results showed that the warming trend during the study period did not have significant impact on wheat yield potential at both sites, and only had significant negative impact on maize yield potential at Beijing. This is in contrast with previous results on effect of warming. The decreasing trend in solar radiation had a much greater impact on simulated yields of both wheat and maize crops, causing a significant reduction in potential yield of wheat and maize at Beijing. Although decreasing trends in rainfed yield of both simulated wheat and maize were found, the substantial interannual variability of precipitation made the trends less prominent.
\end{abstract}

\section{Introduction}

Climate variability and change has been documented to have a major impact on agricultural production in many regions of the world (Rosenzweig and Parry 1994; Brown and Rosenberg 1997; Alexandrov and Hoogenboom 2000; Lobell and Asner 2003; Parry et al. 2004; Tao et al. 2008), especially in semi-humid and semi-arid areas (Thomson et al. 2006; Tao et al. 2003).

C. Chen $(\bowtie) \cdot$ W. E. Baethgen $\cdot$ A. Robertson

International Research Institute for Climate and Society, The Earth Institute at Columbia University, Palisades, NY, USA

e-mail: ccchenchao2009@163.com 
This is particularly the case in the North China Plain (NCP) due to the vulnerability of the intensive cropping system to climate variability and change. The NCP is one of the largest agricultural production regions in China, covering a total area of 320 , $000 \mathrm{~km}^{2}$ and being home to more than 200 million people (Zhang et al. 2005). It plays an important role in maintaining national food security, providing more than $50 \%$ of the wheat and $33 \%$ of the maize produced in China (State Statistics Bureau 1999). However, wheat-maize double cropping system in the NCP is under stress due to shortage in water resources, reduction in cropland area, and the additional impact of climatic change.

In the past four decades, the NCP has become warmer, drier and dimmer, together with large seasonal/interannual climate variability (Che et al. 2005; Liu et al. 2005; Ren et al. 2008; Fu et al. 2009). Air temperature has increased as a result of local industrial development and global warming (Shen and Varis 2001; Tao et al. 2003; Ren et al. 2008). Annual precipitation has exhibited a large interdecadal variability and a decreasing trend (Varis and Vakkilainen 2001; Qian and Lin 2005; Liu et al. 2005). A significant decrease in global solar radiation was found in the NCP resulting from increased atmospheric aerosols caused by human activity (Che et al. 2005; Liang and Xia 2005; Shi et al. 2008; Qian et al. 2006). These variations in climate have been shown to have significant impacts on crop production in the region. A simulation study indicated that the combined effects of the changes in climate variables (temperature, solar radiation and precipitation) since 1961 had a negative impact on potential (i.e. fully irrigated) yield of both wheat and maize crops over the NCP (Chen et al. 2010a). In addition, Liu et al. (2009) found that, if varietal effects were excluded, warming during vegetative stages of wheat and maize (from 1981 to 2000) would have shortened the length of the growing period of both crops, generally leading to a reduction in crop yields. Wu et al. (2006, 2008) reported that climate-related spatial and temporal variability gave rise to substantial yield variability of wheat and maize in the NCP. However, to what extent the crop yield variation could be accounted for by the variability and trend of each individual climate variable remains unclear.

Various approaches, such as statistical regression and simulation models, have been used to investigate crop response to climate variations. For example, Lobell and Asner (2003) used regression statistics to study the relationship between climate variation and observed crop yield in the United States and concluded that corn and soybean yields were both significantly correlated with observed temperature trends, while precipitation and solar radiation had little effects. However, the statistical regression approach is usually limited due to the arbitrary selection of the independent variables for multiple regressions (Spaeth et al. 1987). Crop models, linking meteorological variables with crop growth processes, have been proven to be useful tools to investigate potential impacts of climate variations on crop production (Spaeth et al. 1987; Rosenberg 1993; Easterling et al. 1996; Rosenzweig and Parry 1994).

This study aims to separate the impacts of individual climate factors, i.e. temperature, solar radiation and precipitation, on grain yields of winter wheat and summer maize in the NCP using crop modeling. Specific objectives are to: 1) create climate scenarios for disentangling the impacts of different climate variables on crop yield, 2) provide a quantitative understanding of the impacts of the variability and trends in temperature, solar radiation and precipitation during 1961-2003 on wheat and maize 
yields, and 3) identify the relative contribution of these factors to variations in crop yield during the study period.

\section{Materials and methods}

\subsection{Study sites}

Two study sites, Beijing $\left(39.30^{\circ} \mathrm{N}, 116.28^{\circ} \mathrm{E}\right)$ and Zhengzhou $\left(34.72^{\circ} \mathrm{N}, 113.65^{\circ} \mathrm{E}\right)$, were selected, representing a typical location in northern and southern part of the NCP (Fig. 1). Wu et al $(2006,2008)$ analyzed the spatial and temporal variability of climate (solar radiation, temperature and precipitation) during the wheat and maize seasons based on data from 32 weather stations in the NCP. Their results showed that data from Beijing and Zhengzhou can roughly represent the climate conditions in the northern and southern parts of the NCP, respectively. Another major consideration for site selection is the data availability of daily observed solar radiation, maximum and minimum temperature and precipitation. In terms of spatial change, temperature and precipitation decrease, while accumulated annual solar radiation increases from the south to the north of the NCP. The annual mean air temperature was 12.5 and $14.8{ }^{\circ} \mathrm{C}$ at Beijing and Zhengzhou (1961-2003), respectively. The corresponding annual precipitation at the two sites was 559 and $632 \mathrm{~mm}$, with more than $75 \%$ falling during the summer months (June to September). The accumulated annual solar radiation was 5370 and $5010 \mathrm{MJ} \mathrm{m}^{-2}$ at Beijing and Zhengzhou, respectively.

Winter wheat-summer maize double crop rotation is the currently dominant cropping system in the NCP, including the two study sites. The growing period for winter

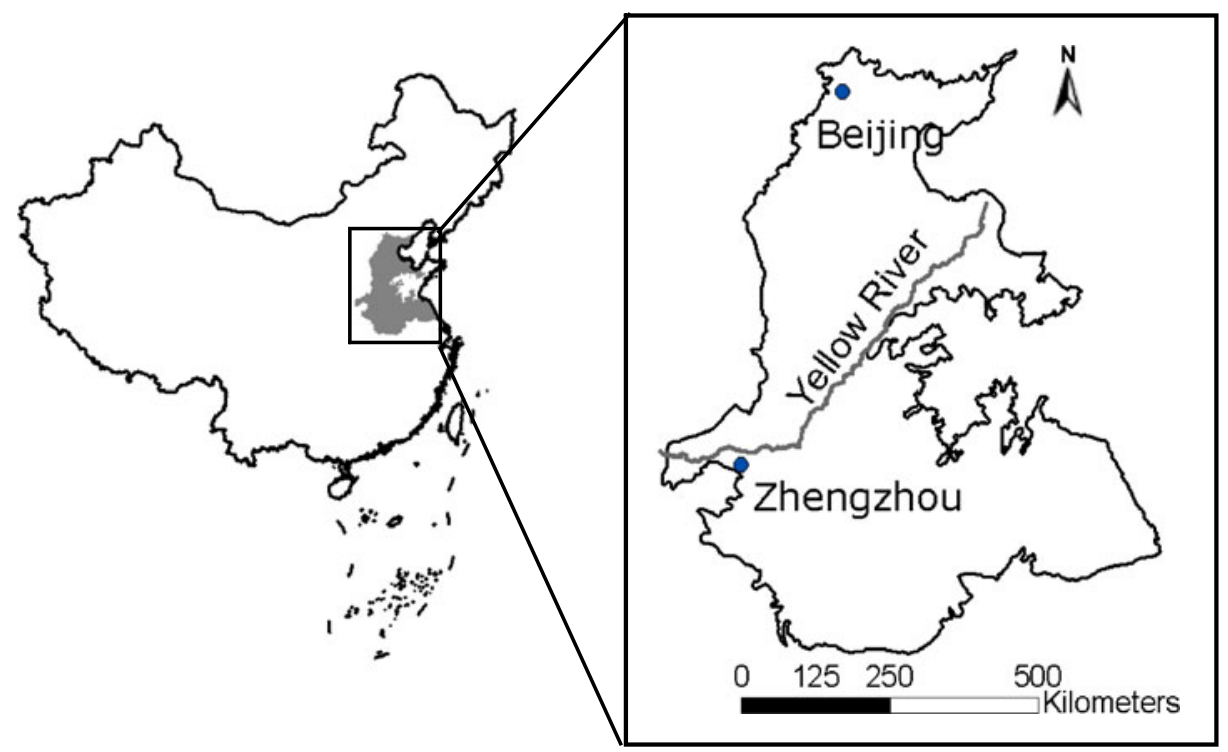

Fig. 1 The North China plain and the two study sites: Beijing and Zhengzhou 


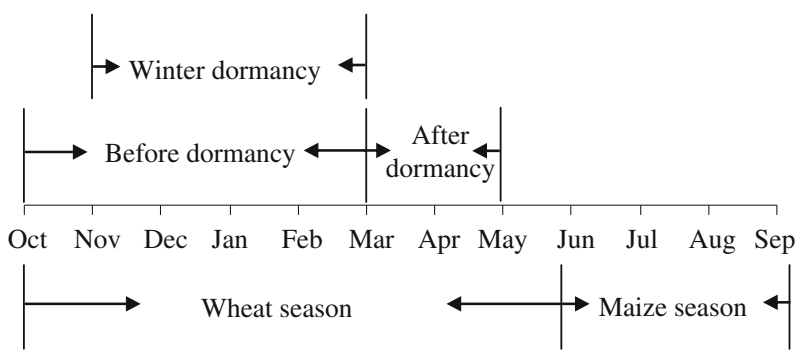

Fig. 2 Timeline of the winter wheat and summer maize growing seasons and the divided growth stages of wheat

wheat is from October to May (Fig. 2). There is a long dormant period from the end of November to the beginning of March, after which winter wheat begins to grow rapidly. In the present study, winter wheat growth period was divided into two stages: before and after dormancy ("turning green"). For summer maize, the growth period is from June to September (Fig. 2).

\subsection{The agricultural system model}

The Agricultural Production Systems Simulator, APSIM version 5.3, (Keating et al. 2003; Wang et al 2002) was used to simulate grain yield of the wheat-maize double cropping system as affected by the variability and trends in climate variables. APSIM is a modular modeling framework developed in Australia. It runs at a daily time step and simulates crop growth and development, yield, soil water and nitrogen dynamics either for single crop or crop rotations in response to climatic and management changes. The following main built-in modules were used in this study: APSIMWHEAT, -MAIZE, -SOILWAT2, -SOILN2, -RESIDUE and the management module (MANAGER). Detailed descriptions of the model structure, its crop and soil modules can be found in Keating et al. (2003) or at the APSIM website: http://www. apsim.info/apsim/.

The APSIM model has been validated and extensively used to predict crop production in Australia and China (Reyenga et al. 2001; Asseng et al. 2004; Luo et al. 2005; Ludwig and Asseng 2006; Wang et al. 2009). In our previous work (Chen et al. 2010a, b, c), we evaluated the model performance in simulating crop growth, development and yield of wheat and maize in the double cropping system and simulated the response of crop productivity to climate variability and trends over the NCP. It was found that the APSIM model was able to reproduce the observed crop growth and yield of wheat and maize in the NCP. The present study builds on the previous work on model calibration and validation and further investigates the impact of changes in individual climate variables on crop yield. The use of APSIM modeling enables crop varieties and agronomic management to be kept constant so that the impacts of climate variables can be separated studied without the compounding effects of other factors. A single variety of wheat, Zhixuan 1, and maize, Yedan 22, was used in the study. They were the varieties planted at the Yucheng experimental station during an experiment conducted from 1997 to 2001 and the derived cultivar parameters by Chen et al. (2010b) were used in the simulations of this study. 


\subsection{Simulation approach}

We used 43 years (1961-2003) of observed daily climate data from the two study sites, obtained from the Bureau of Meteorology, China, as the baseline climate to analyze the combined and interacting effects of temperature, solar radiation and precipitation on wheat and maize grain yield. An ensemble approach was used to separate the impacts of interannual and long-term variations in climate variables on crop yield. A total of 129 climate scenarios were created by constructing synthetic combinations of the three climate variables in the period of 1961-2003. For example, to assess the impact of daily mean temperature, 43 scenarios were generated from the 43-year observed time series. In each scenario, observed temperature values for the entire period (1961-2003) was used, combined with the solar radiation and precipitation data from each individual year starting from 1961. This process was repeated 43 times to create the 43 scenarios (see Table 1). The crop yields simulated using the 43 climate scenarios were averaged for each year to evaluate the impact of temperature trend on crop yield covering all solar radiation and precipitation conditions of 19612003. The same method was used to create climate scenarios for assessing the impacts of solar radiation and precipitation. We also considered the variance ratio:

$$
\rho_{i}=\frac{\sigma_{m e a n, i}^{2}}{\sigma_{\text {all }, i}}
$$

where $\sigma_{\mathrm{all}, \mathrm{i}}^{2}$ is the variance of all the simulated grain yields (i.e. 43 scenarios $\mathrm{x}$ 43 years $=1849$ values) for a given climate variable $i$ (temperature, solar radiation or precipitation) for the period 1961-2003. $\sigma_{\text {mean,i }}^{2}$ is the variance of the corresponding mean simulated grain yields, formed by averaging over the 43 climate scenarios. Analysis of variance (ANOVA) was used to assess the strength of the forcing by the variance of the isolated climate variable (e.g. temperature), relative to the variability of the other two (e.g. solar radiation and precipitation) (Rowel et al. 1995; Rowel 1998).

In the simulations, the same wheat cultivar (Zhixuan 1) and maize cultivar (Yedan 22) were used in all the years and at the two study sites, and the impacts of nutrient stress, disease and pests were not considered. This can help to eliminate the effects of other factors and investigate the impacts of climate factors alone on crop yield. In the simulation, winter wheat was planted on October 5th at Beijing and 15th at Zhengzhou, and harvested at physiological maturity. Maize was planted on June $12^{\text {th }}$ at Beijing and June $15^{\text {th }}$ at Zhengzhou. Maize was intercropped into wheat if wheat was not mature at the maize sowing date, and was harvested 1 day before sowing the next winter wheat crop.

The soil data at two sites included the soil physical and chemical characteristics in different layers and were obtained from the State Soil Survey Service of China (1998).

Crop yield was simulated under full irrigation conditions (i.e. potential yield) for assessing the impacts of temperature and solar radiation in isolation and their combined effects. Crop yield without irrigation (i.e. rainfed) was simulated to evaluate the effects of precipitation. For fully irrigated conditions, it was assumed that water demand of wheat and maize was fully met during the entire growth period. This was achieved using the automatic irrigation facility of the APSIM model. APSIM automatic irrigation was set up in such a way that if soil water content within the 
Table 1 Climate scenarios designed to analyze the effects of the variations in temperature on crop yield in the simulation study

\begin{tabular}{llll} 
Scenarios & Time series of & Time series of & Time series \\
& $\begin{array}{l}\text { Temperature (maximum } \\
\text { and minimum) }\end{array}$ & $\begin{array}{l}\text { Solar } \\
\text { radiation }\end{array}$ & $\begin{array}{l}\text { of } \\
\text { precipitation }\end{array}$ \\
\hline
\end{tabular}

\begin{tabular}{|c|c|c|c|}
\hline 1 & 1961-2003 & 1961 & 1961 \\
\hline 2 & $1961-2003$ & 1962 & 1962 \\
\hline 3 & $1961-2003$ & 1963 & 1963 \\
\hline 4 & $1961-2003$ & 1964 & 1964 \\
\hline 5 & 1961-2003 & 1965 & 1965 \\
\hline 6 & 1961-2003 & 1966 & 1966 \\
\hline 7 & 1961-2003 & 1967 & 1967 \\
\hline 8 & $1961-2003$ & 1968 & 1968 \\
\hline 9 & 1961-2003 & 1969 & 1969 \\
\hline 10 & 1961-2003 & 1970 & 1970 \\
\hline 11 & 1961-2003 & 1971 & 1971 \\
\hline 12 & 1961-2003 & 1972 & 1972 \\
\hline 13 & 1961-2003 & 1973 & 1973 \\
\hline 14 & 1961-2003 & 1974 & 1974 \\
\hline 15 & 1961-2003 & 1975 & 1975 \\
\hline 16 & 1961-2003 & 1976 & 1976 \\
\hline 17 & 1961-2003 & 1977 & 1977 \\
\hline 18 & 1961-2003 & 1978 & 1978 \\
\hline 19 & 1961-2003 & 1979 & 1979 \\
\hline 20 & 1961-2003 & 1980 & 1980 \\
\hline 21 & 1961-2003 & 1981 & 1981 \\
\hline 22 & 1961-2003 & 1982 & 1982 \\
\hline 23 & 1961-2003 & 1983 & 1983 \\
\hline 24 & 1961-2003 & 1984 & 1984 \\
\hline 25 & 1961-2003 & 1985 & 1985 \\
\hline 26 & 1961-2003 & 1986 & 1986 \\
\hline 27 & 1961-2003 & 1987 & 1987 \\
\hline 28 & 1961-2003 & 1988 & 1988 \\
\hline 29 & 1961-2003 & 1989 & 1989 \\
\hline 30 & 1961-2003 & 1990 & 1990 \\
\hline 31 & 1961-2003 & 1991 & 1991 \\
\hline 32 & 1961-2003 & 1992 & 1992 \\
\hline 33 & 1961-2003 & 1993 & 1993 \\
\hline 34 & 1961-2003 & 1994 & 1994 \\
\hline 35 & 1961-2003 & 1995 & 1995 \\
\hline 36 & $1961-2003$ & 1996 & 1996 \\
\hline 37 & 1961-2003 & 1997 & 1997 \\
\hline 38 & 1961-2003 & 1998 & 1998 \\
\hline 39 & 1961-2003 & 1999 & 1999 \\
\hline 40 & 1961-2003 & 2000 & 2000 \\
\hline 41 & 1961-2003 & 2001 & 2001 \\
\hline 42 & 1961-2003 & 2002 & 2002 \\
\hline 43 & 1961-2003 & 2003 & 2003 \\
\hline
\end{tabular}


potential rooting depth $(150 \mathrm{~cm})$ is below $100 \%$ of field capacity, water will be added into the soil to bring the water content within the potential rooting depth to field capacity.

Correlation coefficients between the anomalies of simulated wheat and maize yield and the anomalies of temperature, solar radiation and precipitation, and values of the variance ratio were calculated to detect the relationship between the variability of climate variables and grain yields. The anomalies of crop yields are calculated as the difference between the value of simulated wheat (or maize) yield for each year and the mean value of the 43 years. Linear regression analysis and Kendall-tau statistic (Lobell and Asner 2003; Chmielewski et al. 2004) were used to detect trends in climate variables and simulated crop yields. The annual mean temperature, solar radiation and precipitation and their values during wheat and maize growing seasons were used to calculated their anomalies and trends in the study period.

\section{Results}

\subsection{Variability and trends in climate variables}

At Beijing, anomalies of annual mean temperature during the period 1961-1980 varied between -1.7 and $0.5{ }^{\circ} \mathrm{C}$ (Fig. 3a). The subsequent period (1981-2003) was warmer
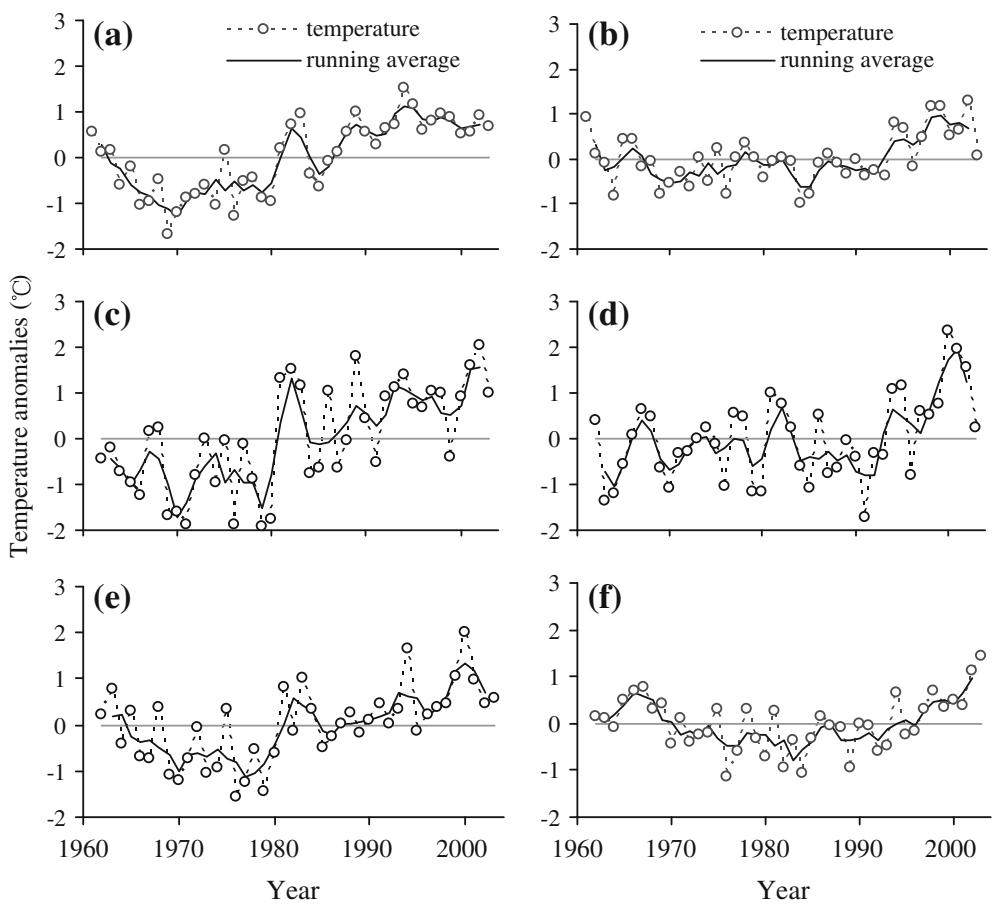

Fig. 3 Anomalies of mean annual temperature $(\mathbf{a}, \mathbf{b})$, mean temperature during the stage after wheat dormancy (c, d) and maize season (e, f) from 1961-2003 at Beijing (left panel) and Zhengzhou (right panel) in the NCP. Smoothed curves show the 3 -yr running average 
Table 2 Trends in mean temperature, solar radiation and precipitation on an annual basis, during the entire wheat season, the stage before wheat winter dormancy (WD1), the stage after winter dormancy (WD2) and during maize season from 1961 to 2003 at the two study sites in the NCP

\begin{tabular}{|c|c|c|c|c|c|c|c|}
\hline \multirow[t]{2}{*}{ Site } & \multirow[t]{2}{*}{ Period } & \multicolumn{2}{|c|}{ Mean temperature } & \multicolumn{2}{|l|}{ Solar radiation } & \multicolumn{2}{|l|}{ Precipitation } \\
\hline & & $\begin{array}{l}\text { Trend } \\
\left({ }^{\circ} \mathrm{C} / \text { decade }\right)\end{array}$ & $\mathrm{R}^{2}$ & $\begin{array}{l}\text { Trend } \\
\left(\mathrm{MJ} / \mathrm{m}^{2} / \text { decade }\right)\end{array}$ & $\mathrm{R}^{2}$ & $\begin{array}{l}\text { Trend } \\
(\mathrm{mm} / \text { decade })\end{array}$ & $\mathrm{R}^{2}$ \\
\hline \multirow[t]{5}{*}{ Beijing } & Annual & $0.43^{* *}$ & 0.46 & $-291.8^{* *}$ & 0.72 & -15.2 & 0.01 \\
\hline & Wheat season & $0.55^{* *}$ & 0.51 & $-161.5^{* *}$ & 0.63 & 7.2 & 0.03 \\
\hline & WD1 & $0.53^{* *}$ & 0.40 & $-86.0^{* *}$ & 0.61 & 3.6 & 0.01 \\
\hline & WD2 & $0.58^{* *}$ & 0.37 & $-76.6^{* *}$ & 0.46 & 3.5 & 0.03 \\
\hline & Maize season & $0.34^{* *}$ & 0.27 & $-131.4^{* *}$ & 0.59 & $-24.1^{*}$ & 0.14 \\
\hline \multirow[t]{5}{*}{ Zhengzhou } & Annual & $0.17^{* *}$ & 0.14 & -57.3 & 0.02 & -5.6 & 0.02 \\
\hline & Wheat season & $0.32^{* *}$ & 0.30 & -36.4 & 0.04 & -4.1 & 0.001 \\
\hline & WD1 & $0.31^{* *}$ & 0.20 & $-34.4^{*}$ & 0.10 & -9.7 & 0.07 \\
\hline & WD2 & $0.31^{* *}$ & 0.17 & -2.5 & 0.001 & -6.0 & 0.01 \\
\hline & Maize season & 0.08 & 0.03 & -18.2 & 0.02 & $-1.1^{*}$ & 0.06 \\
\hline
\end{tabular}

${ }^{* *}$ Significant at $P<0.01$
${ }^{*}$ Significant at $P<0.05$

and included the warmest year of 1994 with an anomaly of $1.54{ }^{\circ} \mathrm{C}$. At Zhengzhou, annual mean temperature fluctuated around the long-term mean till 1993, and then increased thereafter (Fig. 3b). Mean temperature during the whole wheat season and the stage before dormancy showed similar variations with the annual mean temperature (data not shown). Much larger variability was observed in mean temperature after the wheat dormancy (due to the typical strong variation of general circulation in the spring, Fig. 2c, d) as well as in temperature during the maize season (Fig. 3e, f).

Overall, there was a significant trend of increase in mean annual temperature, mean temperature during the stages before and after wheat dormancy and during the
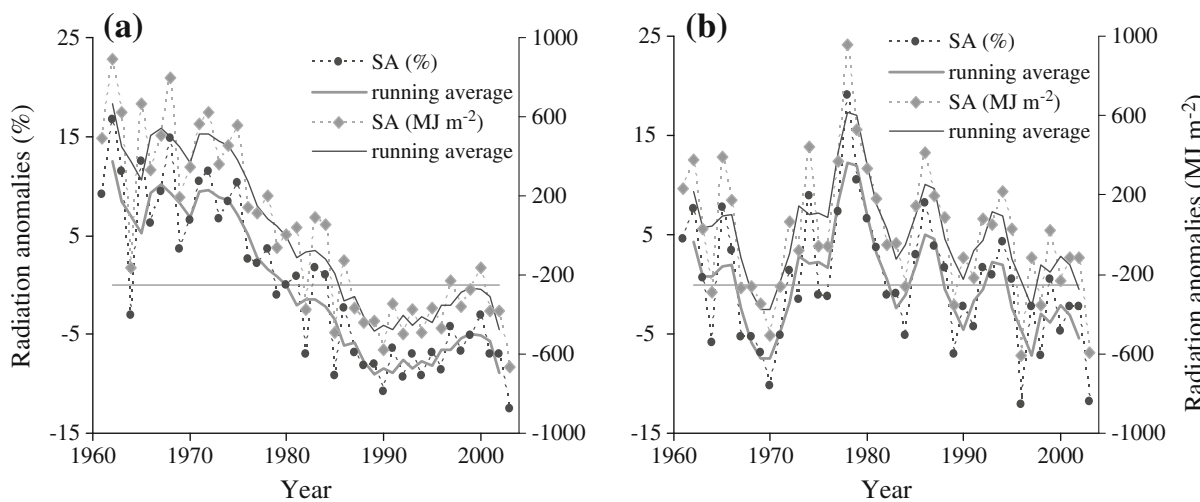

Fig. 4 Annual solar radiation anomalies (SA) (a, b) during 1961-2003 at Beijing (left panel) and Zhengzhou (right panel) in the NCP. Smoothed curves show 3-yr running averages 

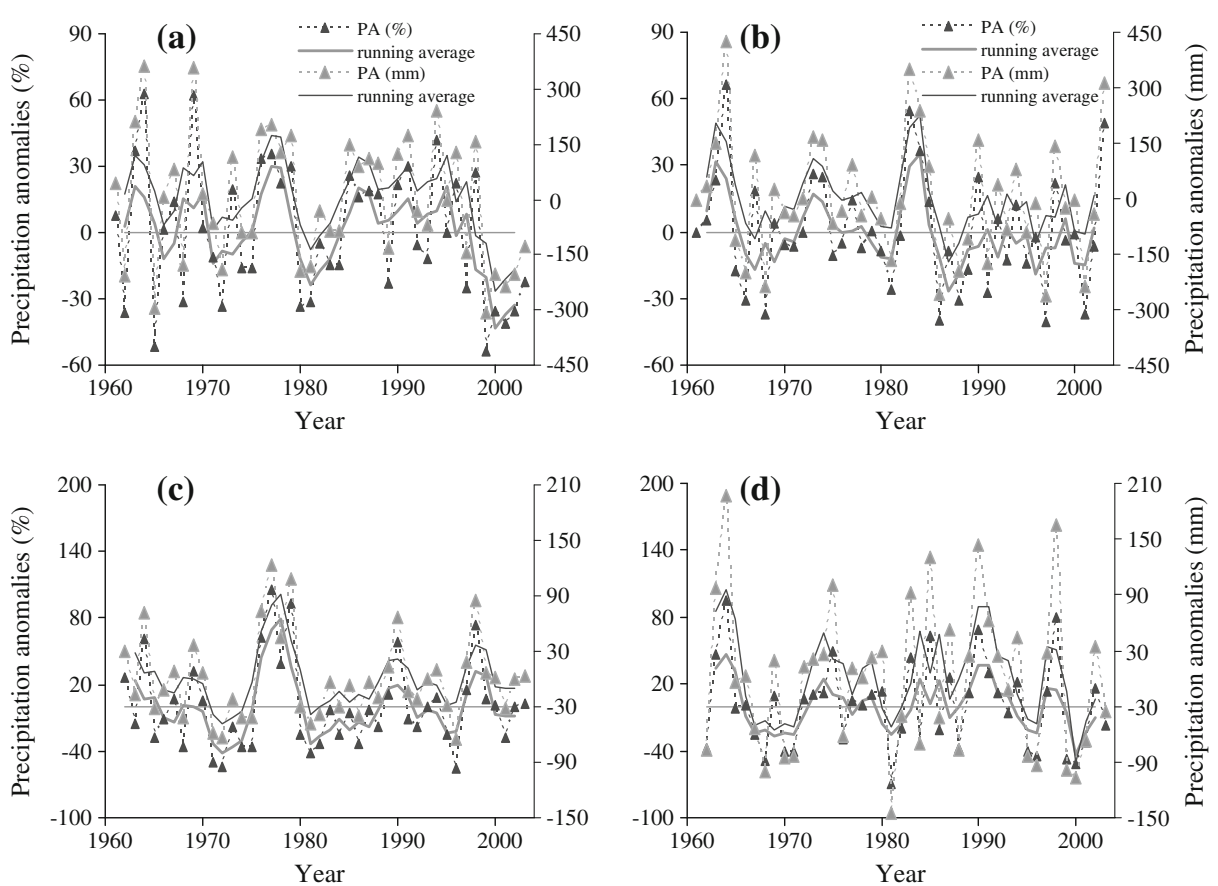

Fig. 5 Anomalies of annual precipitation (a, b) and precipitation during the wheat season (c, d) from 1961-2003 at Beijing (left panel) and Zhengzhou (right panel) in the NCP. Smoothed curves show the 3-yr running averages
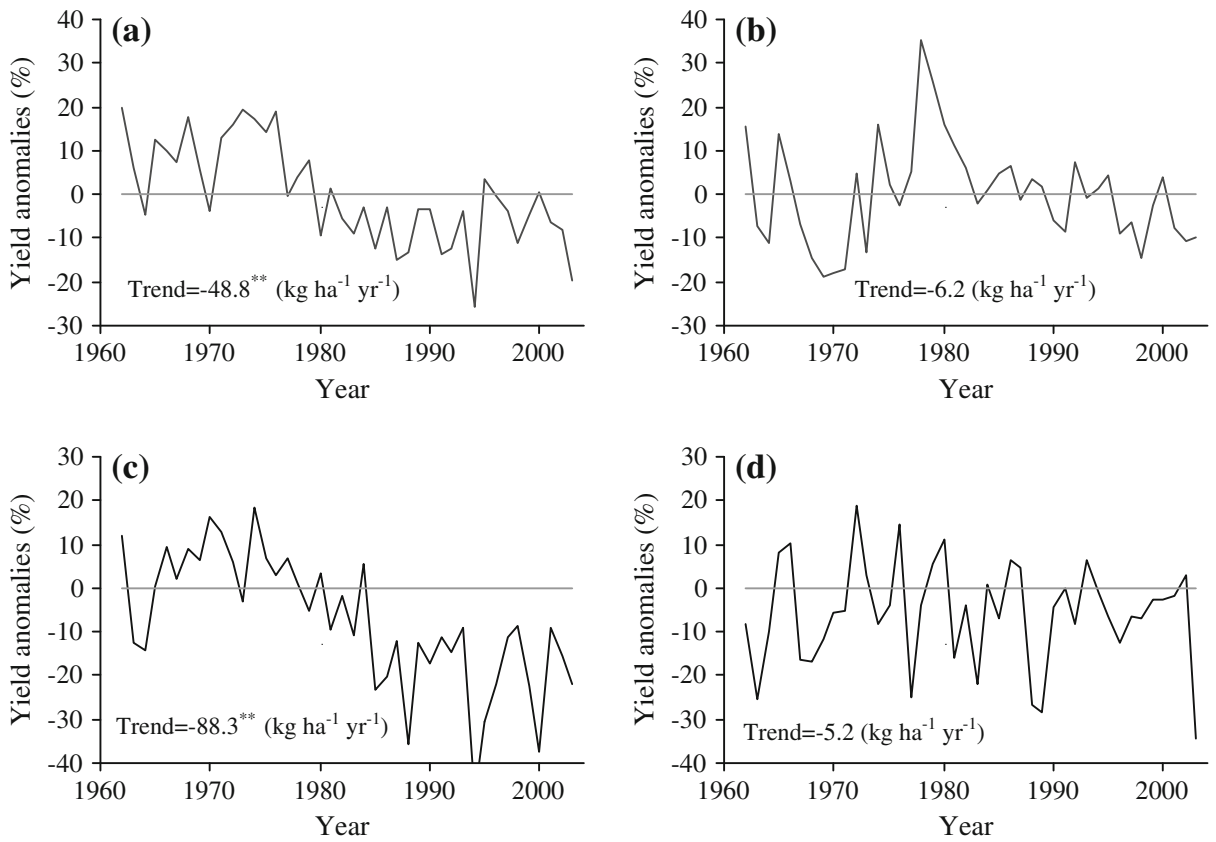

Fig. 6 Anomalies of simulated baseline yields showing the combined effects of temperature, solar radiation and precipitation under potential (fully irrigated) conditions for wheat (panels a, b) and maize (panels c, d) at Beijing (a, c) and Zhengzhou (b, d) 
maize seasons, except during the maize season at Zhengzhou (Table 2). In general, mean temperature increased more during the wheat season than during the maize season as a result of a larger increase in mean temperature in the winter months observed in the NCP.

Annual solar radiation at Beijing showed three distinct periods of change (Fig. 4a): 1960s-1970s solar radiation fluctuated above the long-term mean with no clear trend of change, in 1980s the solar radiation declined linearly, and in 1990s solar radiation tended to stabilize at values below the long-term mean. At Zhengzhou, annual solar radiation declined before 1970, increased from 1970 to 1980 , and showed general declining trend thereafter (Fig. 4b). The highest solar radiation value was observed in 1978, while the lowest values were observed in 1996 and 2003. The variations in solar radiation during the entire wheat season, the stage before and after wheat dormancy and the maize seasons were similar to those in annual solar radiation at two sites (data not shown). Overall, at Beijing, both annual and in-crop (wheat, maize) season solar radiation declined significantly $(p<0.001)$ (Table 2$)$. While the radiation at Zhengzhou also showed a decreasing trend, but the decline was not significant (Table 2).

Annual precipitation at both Beijing and Zhengzhou showed large year-to-year variability (Fig. 5a, b). At Beijing, the variations of precipitation from 1961 to 1984 were characterized by $2-5$ year cycle of fluctuations. The wettest years were 1964 and 1969, with precipitation of about $60 \%$ higher than the average (Fig. 5a). The period of 1985-1998 was a long wet period. After that a dry period was observed and 1999 was the driest year. At Zhengzhou, annual precipitation fluctuated around
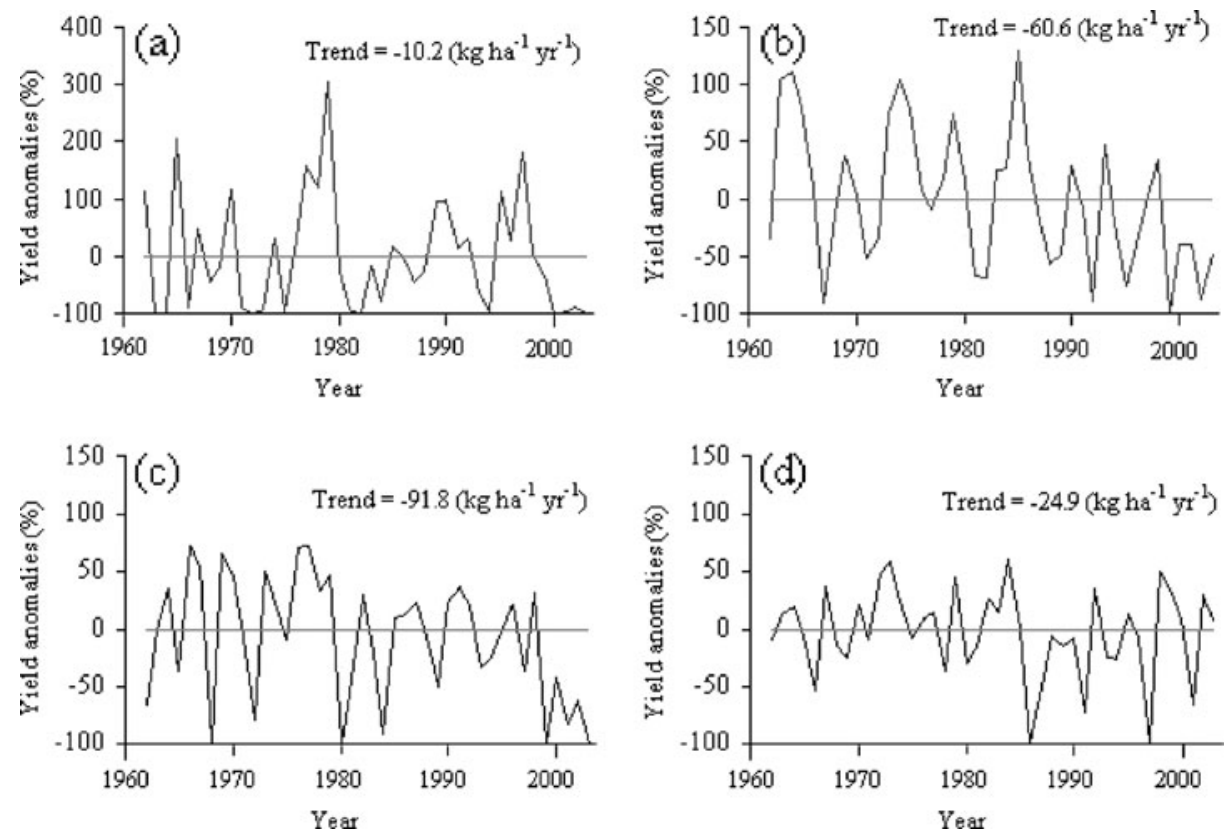

Fig. 7 Anomalies of simulated baseline yields showing the combined effects of temperature, solar radiation and precipitation under rainfed (no irrigation) conditions for wheat (panels a, b) and maize (panels c, d) at Beijing (a, c) and Zhengzhou (b, d) 

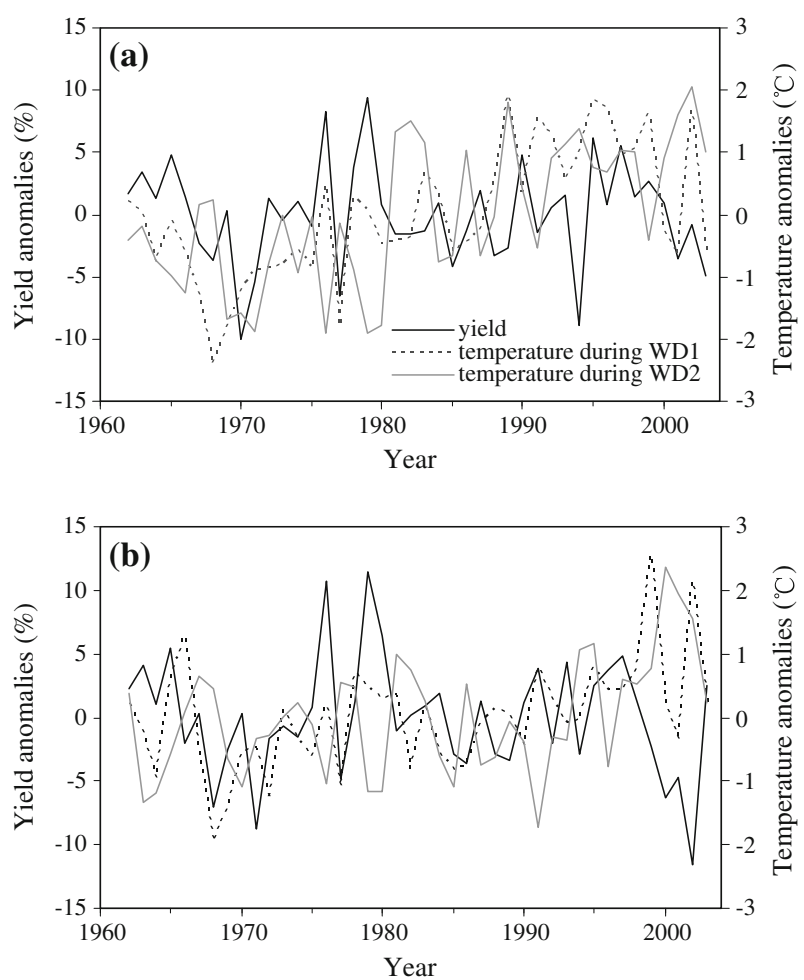

Fig. 8 Isolated impact of temperature variation on simulated wheat yield (\%). Also shown are anomalies of mean temperature $\left({ }^{\circ} \mathrm{C}\right.$ ) during the period before wheat dormancy (WD1) and after wheat dormancy (WD2) of the wheat season at Beijing (a) and Zhengzhou (b)

the long-term mean. There were large interannual variations in precipitation during the entire wheat season (Fig. 5c, d), and the stages before and after wheat dormancy (data not shown). Precipitation during the maize season varied similarly to annual precipitation (data not shown), because $75 \%$ of the annual precipitation falls during the maize season. Only precipitation during the maize season showed significant decreasing trend during the study period at both sites (Table 2).

Table 3 The ratio of variance of mean simulated grain yield $\left(\sigma_{\text {mean }}{ }^{2}\right)$ and that of all simulated grain yields from the ensemble $\left(\sigma_{\text {all }}^{2}\right)$ during 1961-2003. $\sigma_{\text {mean }, \mathrm{T}}^{2} / \sigma_{\text {all,T }}^{2}$ represents the ratio of $\sigma_{\text {mean }}^{2}$ and $\sigma_{\text {all }}^{2}$ where grain yield was affected by temperature; $\sigma_{\text {mean,SR }}^{2} / \sigma_{\text {all,SR }}^{2}$ represents the ratio of $\sigma_{\text {mean }}^{2}$ and $\sigma_{\text {all }}^{2}$ where grain yield was affected by solar radiation; $\sigma_{\text {mean,P }}^{2} / \sigma_{\text {all,P }}^{2}$ represents the ratio of $\sigma_{\text {mean }}^{2}$ and $\sigma_{\text {all }}^{2}$ where grain yield was affected by precipitation

\begin{tabular}{|c|c|c|c|c|c|c|}
\hline \multirow[t]{2}{*}{ Site } & \multicolumn{2}{|c|}{$\sigma_{\text {mean }, \mathrm{T}}^{2} / \sigma_{\mathrm{all}, \mathrm{T}}^{2}$} & \multicolumn{2}{|c|}{$\sigma_{\text {mean }, \mathrm{SR}}^{2} / \sigma_{\mathrm{all}, \mathrm{SR}}^{2}$} & \multicolumn{2}{|c|}{$\sigma_{\text {mean }, \mathrm{P}}^{2} / \sigma_{\mathrm{all}, \mathrm{P}}^{2}$} \\
\hline & Wheat & Maize & Wheat & Maize & Wheat & Maize \\
\hline Beijing & 0.11 & 0.22 & 0.39 & 0.62 & 0.75 & 0.88 \\
\hline Zhengzhou & 0.13 & 0.16 & 0.48 & 0.61 & 0.88 & 0.80 \\
\hline
\end{tabular}


3.2 Impact of the climate variability and trends on simulated crop yield

\subsubsection{Combined impact of temperature, solar radiation and precipitation}

We started by analyzing the crop yield simulations driven by the historical record of temperature, solar radiation and precipitation, based on our early work (Chen et al. 2010a), in which the changes in temperature, solar radiation and precipitation during wheat and maize seasons and their combined effects of these changes on grain yields of wheat and maize were evaluated by using observed daily climate data of 19612003. The simulated result showed that crop yield potential was significantly decreased because of the declined solar radiation together with shortened crop growth period, due to temperature increase. The decline in precipitation also reduced crop yield. The interactions of the three climate variables on crop yield considered here constitute a baseline for subsequent analysis of the contribution of each individual climate variable (see Sections 3.2.2-3.2.4 below).

The simulated baseline wheat and maize yields under both potential and rainfed conditions varied substantially from year to year due to the combined effects of climate variables during the study period (Figs. 6 and 7). Under fully irrigated conditions, anomalies of simulated wheat yield expressed as percentage of the mean, varied from -25.9 to $20.0 \%$ at Beijing and from -18.8 to $35.3 \%$ at Zhengzhou, due to combined effects of temperature and solar radiation anomalies (Fig. 6a, b), while those of simulated maize yield ranged from -47.6 to $18.2 \%$ and
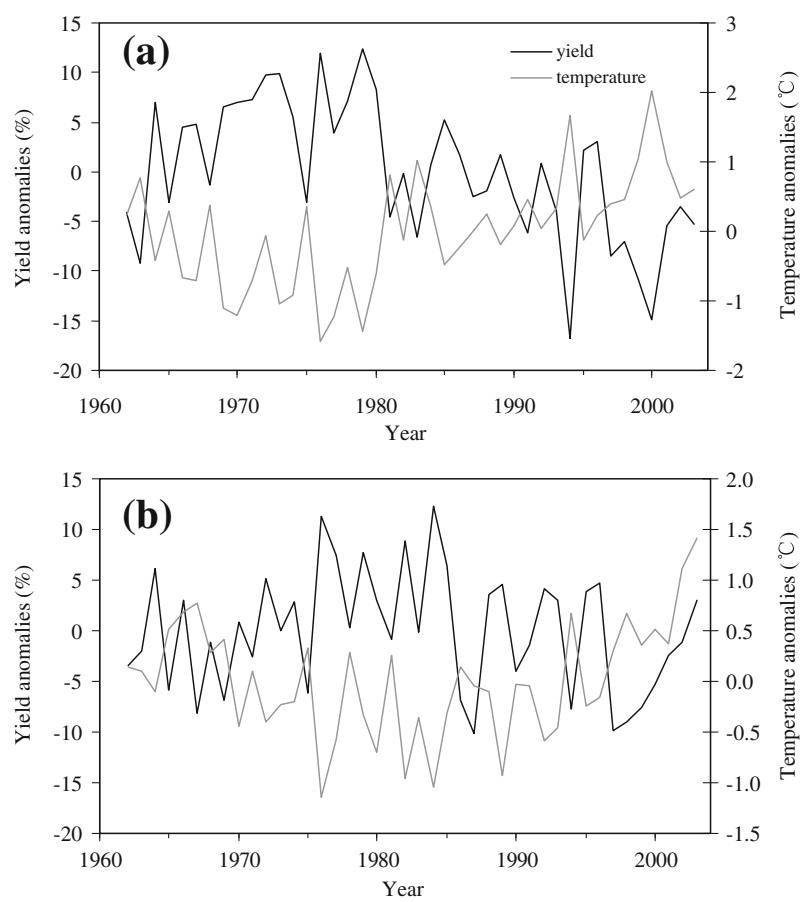

Fig. 9 Anomalies of mean temperature $\left({ }^{\circ} \mathrm{C}\right)$ during the maize growing season and the isolated impact of temperature change on maize yield (\%) at Beijing (a) and Zhengzhou (b) 
-34.6 to $18.9 \%$ at Beijing and Zhengzhou, respectively (Fig. 6c, d). Due to the effects of precipitation change together with changes in temperature and solar radiation, simulated rainfed yield of wheat and maize varied greatly, indicating the large impact of rainfall variability. The minimum yield anomalies were $-100.0 \%$ for both crops at two sites, while the largest yield anomalies were 303.5 and $130.6 \%$ for wheat and 73.4 and $60.5 \%$ for maize at Beijing and Zhengzhou, respectively (Fig. 7a-d).

Due to effects of rising temperature and decline in solar radiation, simulated yield of both wheat and maize under fully irrigated conditions decreased significantly $(p<$ 0.01) from 1960 at Beijing (Fig. 6a, b), while that at Zhengzhou decreased slightly (Fig. 6c, d). Simulated yield of wheat and maize decreased by $48.8 \mathrm{~kg} \mathrm{ha}^{-1} \mathrm{yr}^{-1}$ $\left(-22.6 \% \mathrm{yr}^{-1}\right)$ and $88.3 \mathrm{~kg} \mathrm{ha}^{-1} \mathrm{yr}^{-1}\left(-31.4 \% \mathrm{yr}^{-1}\right)$ at Beijing, respectively. Simulated rainfed yield for both wheat and maize also had decreasing trends at Beijing and Zhengzhou (Fig. 7a-d), due to the combined effects of the decrease in precipitation (except Beijing) together with temperature increase and radiation decrease. However, the reduction in rainfed yield for both crops was not significant at either site $(p>0.05)$.
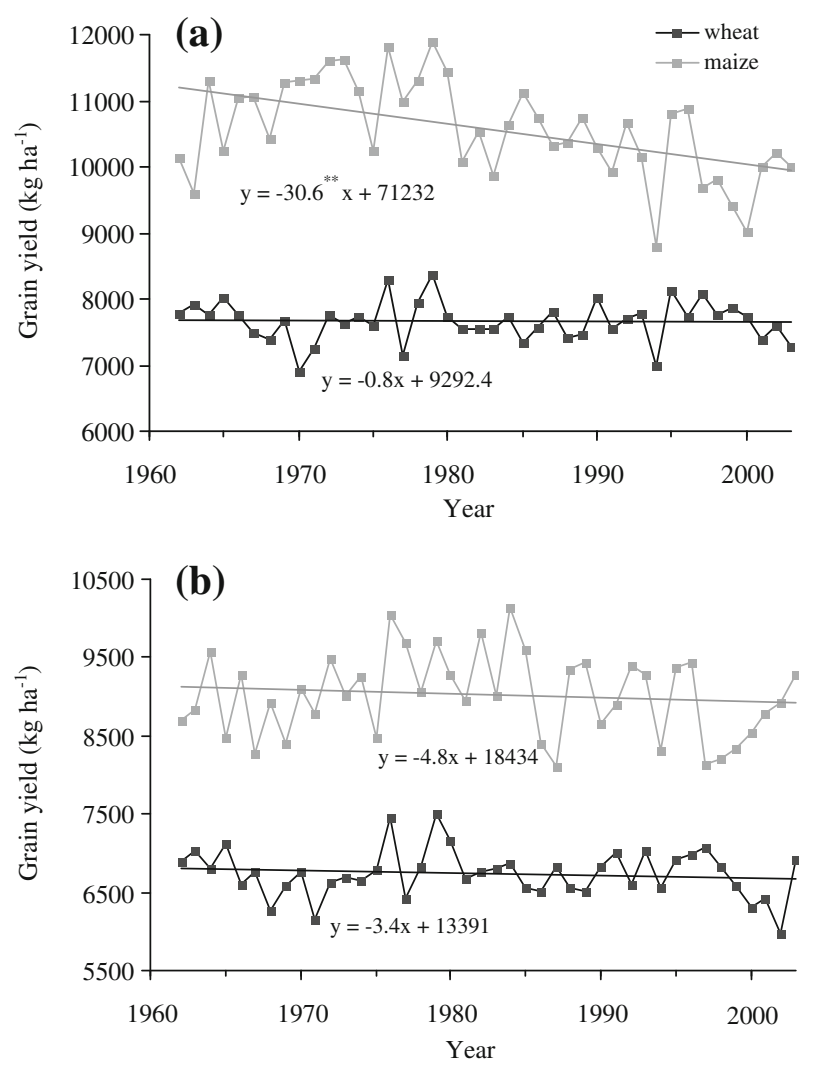

Fig. 10 The simulated yield of wheat and maize under fully irrigated conditions as affected by the changes in temperature from 1962-2003 at Beijing (a) and Zhengzhou (b). Straight lines show the linear trends. ${ }^{* *}$ Significant at $p<0.01$ 


\subsubsection{Isolated Impact of temperature}

Based on the simulation results using the ensemble of 43 climate scenarios in Table 1, temperature change alone caused the anomalies of simulated wheat yield ranging between -10.1 and $9.4 \%$ at Beijing and between -12.5 and $12.1 \%$ at Zhengzhou (Fig. 8). Further analysis on the relationship between simulated wheat yield anomalies and temperature anomalies indicated that higher temperatures before dormancy (WD1) tended to increase wheat yield (possibly due to higher vegetative growth), while a higher temperature after dormancy (WD2) led to wheat yield decrease (due to its effect to shorten the grain filling period) (Fig. 8, Table 3). Temperature change also caused simulated maize yield to vary from year to year during the study period (Fig. 9). Anomalies of simulated maize yield caused by temperature anomalies varied between -16.8 and $13.2 \%$ at Beijing and between -9.9 and $12.8 \%$ at Zhengzhou. Higher temperature during maize season had negative impacts on maize yield due to its effect to shorten the grain filling period.

A trend analysis of the simulated wheat and maize yields is presented in Fig. 10. The simulation results showed that the decrease in mean temperature in the 1960s resulted in decreased wheat yields and the increase in temperature since 1971 had only slightly affected wheat yield at both Beijing and Zhengzhou. Overall, the warming trend during wheat season in the 43 years tended to decrease wheat yields, but the decreasing trend was not significant as a result of the combined positive effects of temperature increase before dormancy and the
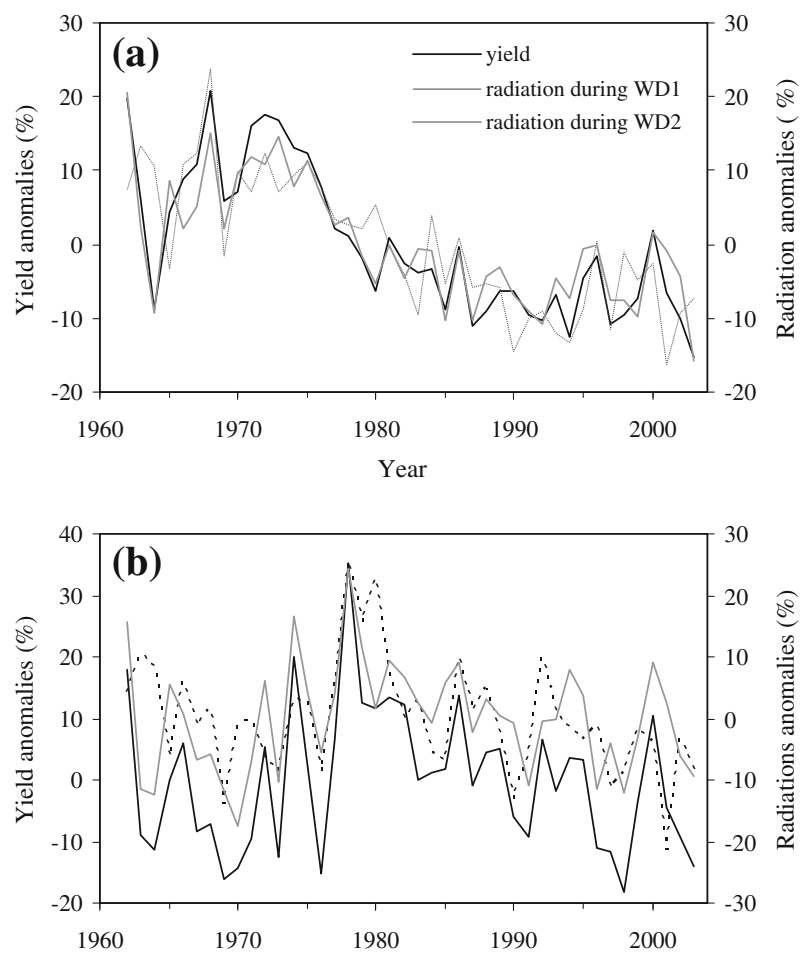

Fig. 11 Isolated impact of solar radiation change on wheat yield (\%) and anomalies of solar radiation (\%) during the stages before wheat dormancy (WD1) and after wheat dormancy (WD2) at Beijing (a) and Zhengzhou (b) 
negative impacts after dormancy. The wheat yield reduction was slightly greater at Zhengzhou than at Beijing. This is mainly due to the fact that the temperature at Zhengzhou is higher, and therefore wheat growth is more sensitive to temperature increase (Fig. 10). The increased temperature during the maize season resulted in a significant reduction of maize yield at the rate of $30.6 \mathrm{~kg} \mathrm{ha}^{-1} \mathrm{yr}^{-1}\left(2.7 \% \mathrm{yr}^{-1}\right)$ at Beijing, and a slight decrease of maize yield at Zhengzhou (Fig. 10).

\subsubsection{Isolated impact of solar radiation}

The observed changes in solar radiation resulted in anomalies of simulated wheat yield (ensemble mean of the 43 scenarios) that varied from -16.7 to $20.0 \%$ and -18.5 to $36.6 \%$ at Beijing and Zhengzhou, respectively (Fig. 11, Table 3). The simulated results indicate that changes in wheat yield almost coincided with changes in solar radiation (Fig. 11). Anomalies of simulated maize yield caused by changes in solar radiation anomalies varied between -29.8 and $24.8 \%$ at Beijing and between -24.9 and $23.8 \%$ at Zhengzhou (Fig. 12). In general, negative anomalies of solar radiation during crop growing season led to lower crop yield due to reduced photosynthetically active radiation captured by the crops for biomass and yield production.

These results suggest that the reduction in solar radiation observed in Beijing led to significant decline in grain yields of both wheat and maize in the 43 years of our study (Fig. 13). At Zhengzhou, decline in solar radiation from the mid 1970 also caused decline in wheat yield. From 1961 to 2003, simulated yield decreased by $43.9 \mathrm{~kg} \mathrm{ha}^{-1} \mathrm{yr}^{-1}\left(5.2 \% \mathrm{yr}^{-1}\right)$ for wheat and $54.9 \mathrm{~kg} \mathrm{ha}^{-1} \mathrm{yr}^{-1}\left(4.8 \% \mathrm{yr}^{-1}\right)$ for maize at Beijing. The greater reduction in
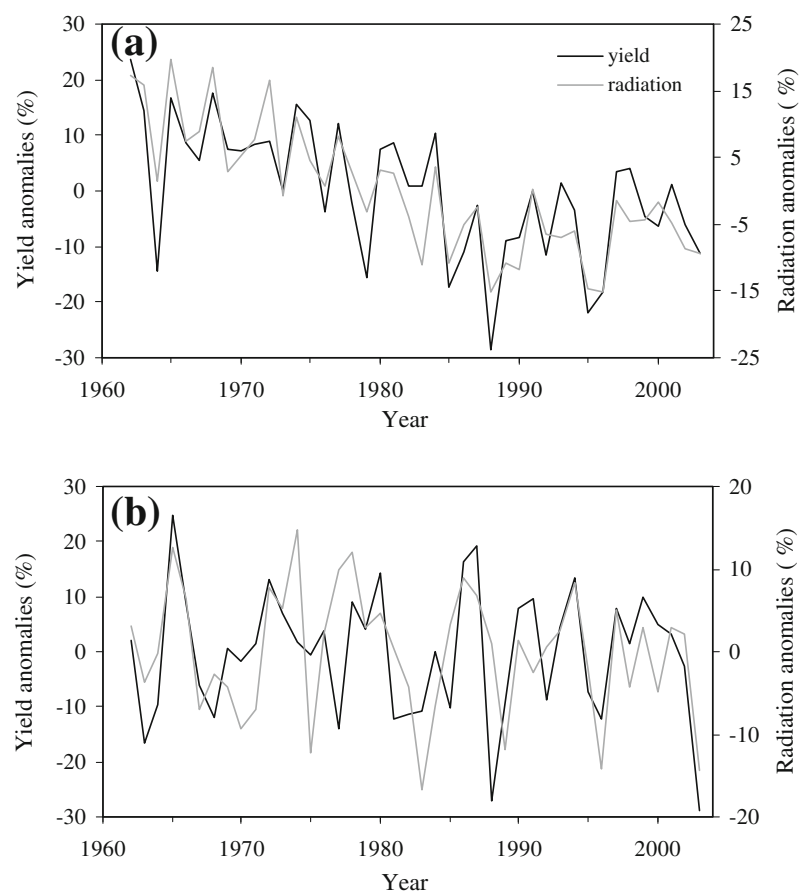

Fig. 12 Isolated impact of solar radiation change on maize yield (\%) and anomalies of solar radiation (\%) during the maize season at Beijing (a) and Zhengzhou (b) 

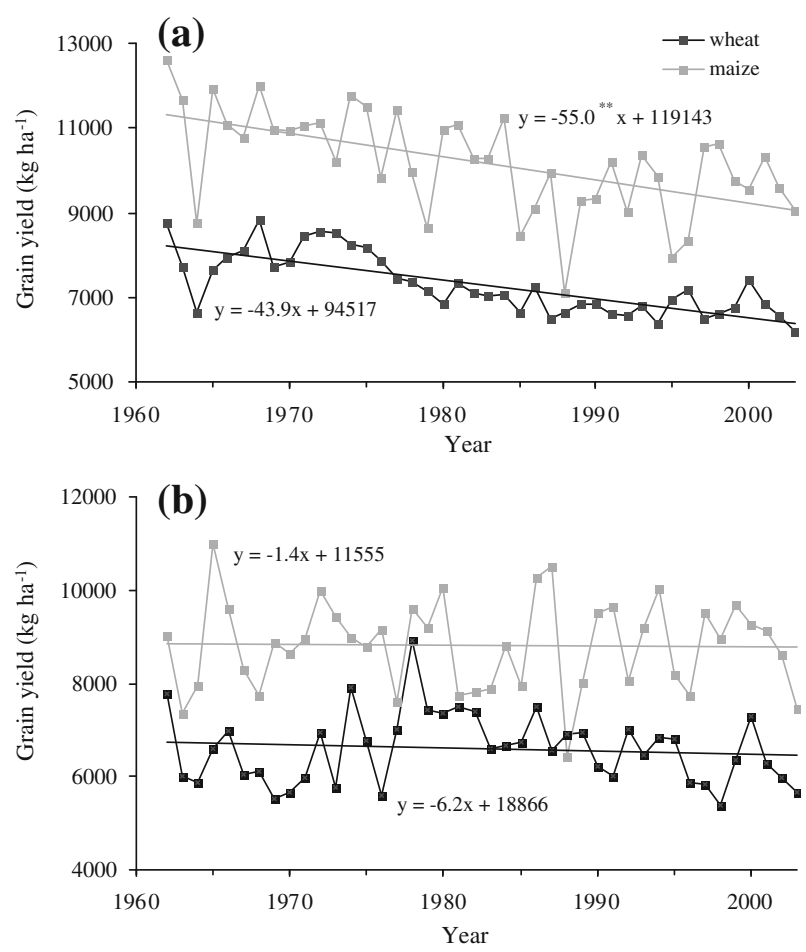

Fig. 13 The simulated yield of wheat and maize under fully irrigated conditions as affected by the trends in solar radiation from 1962-2003 at Beijing (a) and Zhengzhou (b). Straight lines show the linear trends. ${ }^{* *}$ Significant at $p<0.01$

solar radiation observed in Beijing (Fig. 4g) caused the greater reduction in crop yield as compared to Zhengzhou.

\subsubsection{Isolated impact of precipitation}

Due to the big variability in precipitation in the NCP (Fig. 5), both wheat and maize yields under rainfed conditions were very sensitive to the variations of precipitation (Figs. 14 and 15). Wheat yield in high rainfall seasons was three- to four-fold higher than the average, while in some drier seasons, there was no grain yield produced (crop failure). Compared to wheat, anomalies of maize yield were smaller due to the concentrated precipitation during the maize season, but the variations were still large due to inter-seasonal precipitation variability (Fig. 5).

The simulation results show that changes in precipitation tended to reduce crop yields under rainfed conditions at both sites (Fig. 16). However, simulated rainfed yield exhibited great inter-annual variability caused by the interannual variation of precipitation.

\section{Discussion and conclusions}

This study used a modeling approach, with climate scenarios built from combinations of observed climate variables, i.e. temperature, solar radiation and precipitation, and fixed crop 

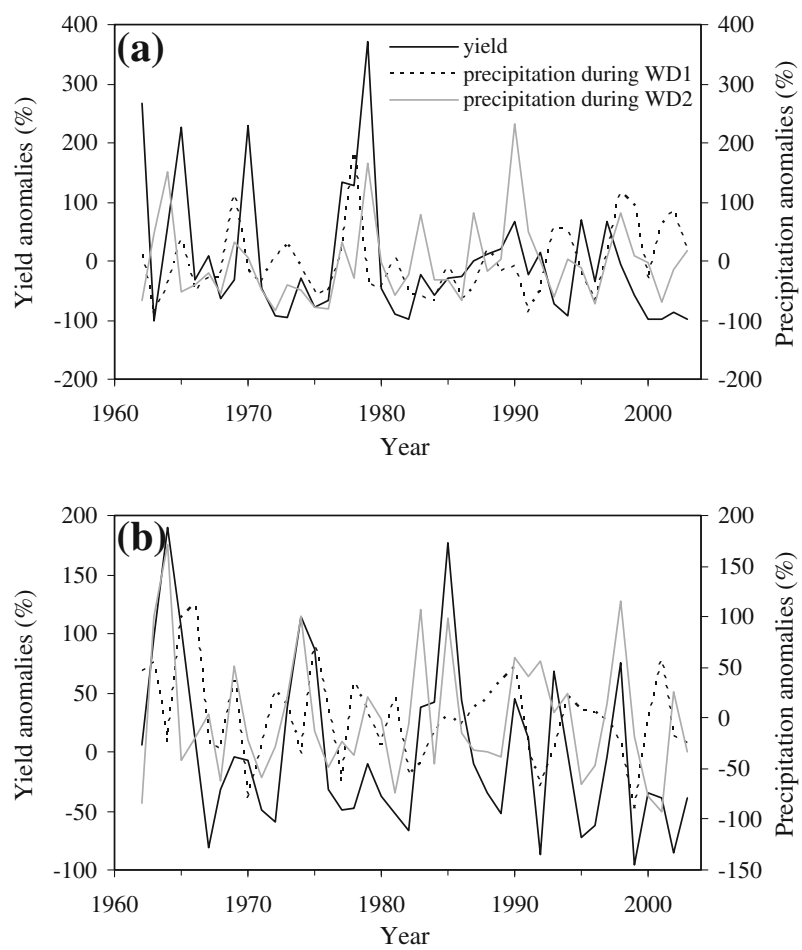

Fig. 14 Isolated impact of precipitation change on wheat yield (\%) and anomalies of precipitation (\%) during the stages before wheat dormancy (WD1) and after wheat dormancy (WD2) at Beijing (a) and Zhengzhou (b)

cultivars, to disentangle the influence of the observed changes in climate variables on crop yields. Different combinations of each individual climate variable with other variables during the study period were considered. This approach enabled us to quantify the changes in crop yield caused by each individual climate variable in absence of changes in other climate variables and management conditions. Due to the compounding effects of changes in climate, in crop varieties and management practices, measured crop yield cannot be directly used to assess contributions of variations in individual climate variables. Compared with other studies using regression analyses to investigate the impacts of climate variables and agronomic management on crop yields (Thompson 1962; Dirks and Bolton 1981; Lobell et al. 2007), our approach demonstrates that cropping modeling is an effective means to decouple the compounding effects.

A significant warming trend was observed over the last four decades at the two study sites, accompanied by a declining trend in solar radiation and precipitation. The impacts of those changes on crop yield were not uniform during different crop stages and across the NCP. Higher temperatures before the wheat dormancy stage had a positive effect on yields, especially in the northern part of the NCP, while increased temperatures after dormancy decreased wheat yield. In the NCP, the growth and yield of winter wheat is often affected by frost damage during the winter (Jin 1996). The higher temperatures during the winter lessen the frost impacts on winter wheat and lead to high grain yields. However, temperature increase during the stage after dormancy shortens the growing period for winter wheat which results in a shorter grain-filling stage, less accumulation of biomass and hence lower grain 

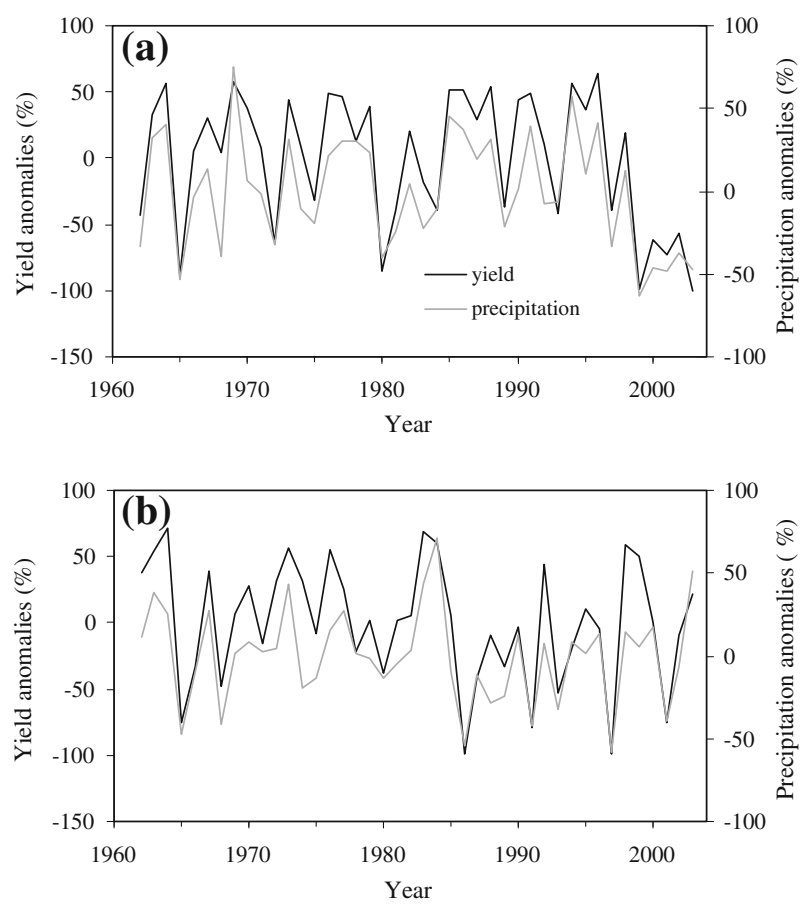

Fig. 15 Isolated impact of precipitation variation on maize yield (\%) and anomalies of precipitation (\%) during the maize season at Beijing (a) and Zhengzhou (b)

yield (Song et al. 2006). Maize was negatively impacted by rising temperatures mainly due to shortened growing seasons. In general, changes in temperature only had significant impact on maize yield at Beijing, and changes in radiation had a bigger impact on yield of both crops, particularly in Beijing. The variability of wheat yield was mainly linked to the variability of solar radiation during the stage after dormancy. Under rainfed conditions, precipitation is the most important climate factor affecting crop yield in the NCP. Rainfed grain yield for both wheat and maize varied greatly with precipitation variability. The results here are a further addition to the combined impact of changes in climate variables presented in Chen et al. (2010a).

Previous studies (Tao et al. 2006; Liu et al. 2009) showed that climate change in the past few decades led to negative impacts on crop yield potential in the NCP and especially emphasized the role played by the warming trend. Tao et al. (2006) reported that maximum and minimum temperature in winter and spring during 1981-2000 at Zhengzhou were negatively related to wheat yields based on Pearson correlation analyses. Figure 17 shows the statistical relationship of temperature and our simulated baseline wheat yield at Beijing. A similar relationship can be seen showing that wheat yield decreased with increased temperature. However, these results are misleading because the effects of solar radiation change were not excluded. Our simulation results indicated that the change in temperature alone did not lead to significant change in wheat yield (Fig. 9), while decline in solar radiation caused a decline in simulated yields. This further highlights the effectiveness of the modeling approach to disentangle the impact of individual driving variables on crop yield.

The warming trend is predicted to continue in the future 20 to 100 years in NCP, with a warming rate dependent on emission scenarios (Ding et al. 2007). The projected higher 

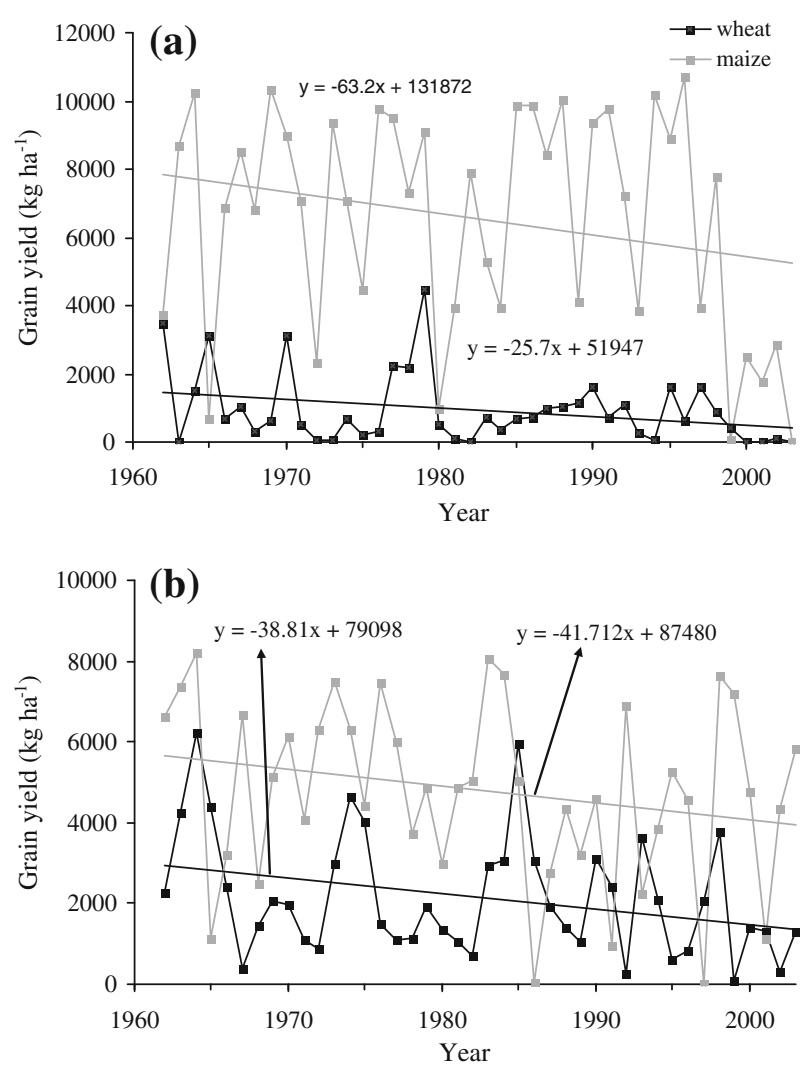

Fig. 16 The simulated yield of wheat and Maize under rainfed conditions affected by the changes in precipitation from 1962-2003 at Beijing (a) and Zhengzhou (b). Straight lines show the linear trends

temperature can become more deleterious to crop productivity by accelerating crop growth and development process and shortening the length of the growing season. Annual
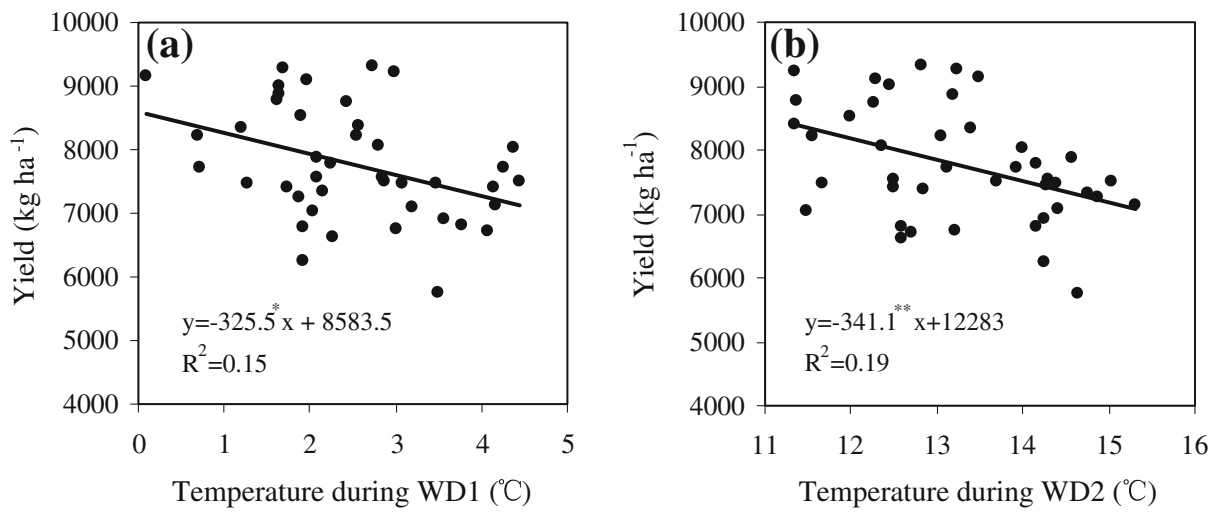

Fig. 17 Relationship between simulated wheat potential yield and mean temperature during the stages before wheat dormancy (WD1) (a) and after wheat dormancy (WD2) (b) at Beijing 
precipitation is projected to be likely increased in the NCP, but with large uncertainty due to the complicated dynamic mechanisms of precipitation variation. Change in solar radiation is also uncertain. One scenario would be that environmental conditions are not improved due to industrial development, and in this case decreased solar radiation would further reduce crop potential yields in the near future. If emission of aerosols can be reduced (Wild et al. 2005), solar radiation may increase. However, an increase in solar radiation, together with the projected warming, could worsen the water shortage problem in the NCP, which may result in decreased crop yield due to increased crop water stress. Our results indicate that studies on future radiation change and its impacts on crop production must take into account in future studies.

Although increased temperature, decreased solar radiation and precipitation have been shown to negatively affect crop production, actual wheat and maize yields have been increased greatly since the 1960s in the NCP (Wu et al. 2006, 2008). Such increase is mainly attributed to improved cultivars, as well as increased inputs (irrigation and fertilization), and improved agronomic practices (Chameides et al. 1999; Mellouli et al. 2000; Zhu and Chen 2002; Evenson and Gollin 2003; Qaim and Zilberman 2003; Zhang et al. 2005). The improved crop variety have led to extended growth period and increased harvest index, which was able to compensate the negative impact of climatic change (Liu et al. 2009; Parry et al. 2005). Further research is needed to breed crop varieties that are better adapted to changes in climate.

In summary, our ensemble simulation approach enabled to disentangle the impact of changes in individual climate variables (temperature, solar radiation and precipitation). It reveals the temperature change only had significant and negative impact on maize crop in northern NCP, while had no significant impact on wheat yield across NCP and on maize yield in southern NCP. The decline in solar radiation had a much greater negative impact on yields of both wheat and maize crops, particularly in northern NCP. The decrease in wheat yield caused by solar radiation was 53.8 times and 1.8 times larger than that caused by temperature at Beijing and Zhengzhou, respectively. The corresponding decrease in maize yield was 1.8 times at Zhengzhou. Decreasing precipitation resulted in a decreasing trend in rainfed yield of both wheat and maize, but the large year-to-year variability of precipitation made the yield trends less prominent.

Acknowledgments The authors are grateful to Enli Wang and Qiang Yu for their useful and critical comments. This work was supported by grants from National Oceanic and Atmospheric Administration (NOAA), NA050AR4311004, and the Earth Institute at Columbia University.

\section{References}

Alexandrov VA, Hoogenboom G (2000) The impact of climate variability and change on crop yield in Bulgaria. Agric For Meteorol 104(4):315-327

Asseng S, Jamieson PD, Kimball B, Pinter P, Sayre K, Bowdenand JW, Howden SM (2004) Simulated wheat growth affected by rising temperature, increased water deficit and elevated atmospheric $\mathrm{CO}_{2}$. Field Crop Res 85:85-102

Brown RA, Rosenberg NJ (1997) Sensitivity of crop yield and water use to change in a range of climatic factors and $\mathrm{CO}_{2}$ concentrations: a simulation study-applying EPIC to the central USA. Agric For Meteorol 83:171-203

Chameides WL, Yu H, Liu SC, Bergin M, Zhou X, Mearns L, Wang G, Kiang CS, Saylor RD, Luo C, Huang Y, Steiner A, Giorgi F (1999) Case study of the effects of atmospheric aerosols and regional haze on agriculture: an opportunity to enhance crop yields in China through emission controls? Proc Natl Acad Sci USA 96:13626-13633 
Che HZ, Shi GY, Zhang XY, Arimoto R, Zhao JQ, Xu L, Wang B, Chen ZH (2005) Analysis of 40 years of solar radiation data from China, 1961-2000. Geophys Res Lett 32:1-5

Chen C, Wang EL, Yu Q, Zhang YQ (2010a) Quantifying the effects of climate trends in the past 43 years (1961-2003) on crop growth and water demand in the North China Plain. Clim Change 100:559-578

Chen C, Wang EL, Yu Q (2010b) Modeling Wheat and maize Productivity as affected by climate variation and irrigation supply in North China Plain. Agron J 102:1037-1049

Chen C, Wang EL, Yu Q (2010c) Modeling the effects of climate variability and water management on crop water productivity and water balance in the North China Plain. Agric Water Manage 97(8):1175-1184

Chmielewski FM, Müller A, Bruns E (2004) Climate changes and trends in phenology of fruit trees and field crops in Germany, 1961-2000. Agric For Meteorol 121:69-78

Ding YH, Ren GY, Shi GY, Zhao ZC (2007) China's National Assessment Report on climate change (I): climate change in China and the future trend. Adv Clim Change Res 3(Suppl):1-5

Dirks VA, Bolton EF (1981) Climatic factors contributing to year-to-year variation in grain yield of corn on Brookston clay. Can J Plant Sci 61:293-305

Easterling WE, Chen XF, Hay C, Brandle J, Zhang HH (1996) Improving the validation of model-simulated crop yield response to climate change: an application to the EPIC model. Clim Res 6:263-273

Evenson RE, Gollin D (2003) Assessing the impact of the green revolution, 1960 to 2000. Science 300:758762

Fu GB, Charles SP, Yu JJ, Liu CM (2009) Decadal climate variability, trends and future scenarios for the North China Plain. J Clim 22:2111-2123

Jin SB (1996) Winter wheat in China. China Agriculture Publishing House, Beijing, pp 766-768

Keating BA, Carberry PS, Hammer GL, Probert ME, Robertson MJ, Holzworth D, Huth NI, Hargreaves JNG, Meinke H, Hochman Z, McLean G, Verburg K, Snow V, Dimes JP, Silburn M, Wang EL, Brown S, Bristow KL, Asseng S, Chapman S, McCown RL, Freebairn DM, Smith CJ (2003) An overview of APSIM, a model designed for farming systems simulation. Eur J Agron 18:267-288

Liang F, Xia XA (2005) Long-term trends in solar radiation and the associated climatic factors over China for 1961-2000. Ann Geophys 23:2425-2432

Liu BH, Xu M, Henderson M, Qi Y (2005) Observed trends of precipitation amount, frequency, and intensity in China, 1960-2000. J Geophys Res 110:D08103. doi:10.1029/2004JD004864

Liu Y, Wang EL, Yang XG, Wang J (2009) Contributions of climatic and crop varietal changes to crop production in the North China Plain, since 1980s. Global Change Biol. doi:10.1111/j.13652486.2009.02077.x

Lobell DB, Asner G (2003) Climate and management contributions to recent trends in U.S. agricultural yields. Science 299:1032

Lobell DB, Cahill KN, Field CB (2007) Historical effects of temperature and precipitation on California crop yield. Clim Change 81:187-203

Ludwig F, Asseng S (2006) Climate change impacts on wheat production in a Mediterranean environment in Western Australia. Agric Syst 90:159-179

Luo QY, Bellotti W, Williams M, Bryanc B (2005) Potential impact of climate change on wheat yield in South Australia. Agric For Meteorol 132:273-285

Mellouli HJ, van Wesemael B, Poesen J, Hartmann R (2000) Evaporation losses from bare soils as influenced by cultivation techniques in semi-arid regions. Agric Water Manag 42:355-369

Parry ML, Rosenzweig C, Iglesias A, Livermore M, Fischer G (2004) Effects of climate change on global food production under SRES emissions and socio-economic scenarios. Glob Environ Change 14:53-67

Parry M, Rosenzweig C, Livermore M (2005) Climate change, global food supply and risk of hunger. Phil Trans R Soc B 360:2125-2138

Qaim M, Zilberman D (2003) Yield effects of genetically modified crops in developing countries. Science 299:900-901

Qian W, Lin X (2005) Regional trends in recent precipitation indices in China. Meteorol Atmos Phys 90:193-207

Qian Y, Kaiser DP, Leung LR, Xu M (2006) More frequent cloud-free sky and less surface solar radiation in China from 1955 to 2000. Geophys Res Lett 33:L01812. doi:10.1029/2005GL024586

Ren GY, Zhou YQ, Chu ZY, Zhou JX, Zhang AY, Guo J, Liu XF (2008) Urbanization effects on observed surface air temperature trends in North China. J Clim 21(6):1333-1348

Reyenga PJ, Howden SM, Meinke H, Hall WB (2001) Global change impacts on wheat production along an environmental gradient in south Australia. Environ Int 27:195-200

Rosenberg NJ (1993) Towards an integrated assessment of climate change: the MINK study. Clim Change $24: 1-175$

Rosenzweig C, Parry M (1994) Potential impact of climate change on world food supply. Nature 367:133-138

Rowel DP (1998) Assessing potential seasonal predictability with an ensemble of multidecadal GCM simulations. J Clim 11:109-120 
Rowel DP, Folland CK, Maskell K, Ward MN (1995) Variability of summer rainfall over tropical North Africa (1962-92): observations and modeling. Quart J R Met Soc 121:669-704

Shen DJ, Varis O (2001) Climate change in China. Ambio 30:381-383

Shi GY, Hayasaka T, Ohmura A, Chen ZH, Wang B, Zhao JQ, Che HZ, Xu L (2008) Data quality assessment and the long-term trend of ground solar radiation in China. J Appl Meteorol Clim 47(4):1006-1017

Song YL, Chen DL, Dong WJ (2006) Influence of climate on winter wheat productivity in different climate regions of China, 1961-2000. Clim Res 32:219-227

Spaeth SC, Sinclair TR, Ohnuma T, Konno S (1987) Temperature, radiation, and duration dependence of high soybean yields: measurements and simulation. Field Crop Res 16:297-307

State Soil Survey Office of China (1998) Soils in China. Chinese Agricultural Press House, Beijing

State Statistics Bureau (1999) Statistics yearbook of China. Statistics Publishing House, Beijing

Tao FL, Yokozawa M, Hayashi Y, Lin ED (2003) Future climate change, the agricultural water cycle, and agricultural production in China. Agric Ecosys Environ 95:203-215

Tao FL, Yokozawa M, Xu YL, Hayashi Y, Zhang Z (2006) Climate changes and trends in phenology and yields of field crops in China, 1981-2000. Agric For Meteorol 138:82-92

Tao FL, Hayashi Y, Zhang Z, Sakamoto T, Yokozawa M (2008) Global warming, rice production, and water use in China: developing a probabilistic assessment. Agric For Meteorol 148(1):94-110

Thompson LM (1962) Evaluation of weather factors in the production of wheat. J Soil Water Conserv 17:149156

Thomson AM, Izaurralde RC, Rosenberg NJ, He XX (2006) Climate change impacts on agriculture and soil carbon sequestration potential in the Huang-Huai-Hai Plain of China. Agric Ecosys Environ 114:195-209

Varis O, Vakkilainen P (2001) China's 8 challenges to water resources management in the first quarter of the 21 st century. Geomorphology 41:93-104

Wang E, Robertson MJ, Hammer GL, Carberry PS, Holzworth D, Meinke H, Chapman SC, Hargreaves JNG, Huth NI, McLean G (2002) Development of a generic crop model template in the cropping system model APSIM. Eur J Agron 18(1-2):121-140

Wang J, Wang EL, Luo QY, Kirby M (2009) Modelling the sensitivity of wheat growth and water balance to climate change in Southeast Australia. Clim Change 96:79-96

Wild M, Gilgen H, Roesch A, Ohmura A, Long CN, Dutton EG, Forgan B, Kallis A, Russak V, Tsvetkov A (2005) From dimming to brightening: decadal changes in solar radiation at earth's surface. Science 308:847-850

Wu DR, Yu Q, Lu CH, Hengsdijk H (2006) Quantifying production potentials of winter wheat in the North China Plain. Eur J Agron 24:226-235

Wu DR, Yu Q, Wang EL, Hengsdijk H (2008) Impact of spatial-temporal variations of climatic variables on summer maize yield in the North China Plain. Int J Plant Prod 2:1-18

Zhang XY, Chen SY, Liu MY, Pei D, Sun HY (2005) Improved water use efficiency associated with cultivars and agronomic management in the North China Plain. Agron J 97:783-790

Zhu ZL, Chen DL (2002) Nitrogen fertilizer use in China-contributions to food production, impacts on the environment and best management strategies. Nutr Cycl Agroecosyst 63:117-127 